\title{
Planetologists of the Solar System, unite
}

\section{European planetary scientists are up in arms for lack of spacecraft and their US colleagues are no better off. They should get together and decide what they want to do.}

THAT turbulent body of men and women consisting of Europe's planetary scientists is once more up in arms, its anger on this occasion directed against the European Space Agency. The issue is at once complicated and simple. The agency, being by constitution a consortium of mutuallyjealous governments, conducts its affairs by means of a complicated interlocking hierarchy of advisory committees. The committees necessarily advise the council, whose decision is constitutionally final, and whose awareness of what the agency has to spend is necessarily more acute than that of its advisers. At the council's next meeting, two weeks from now, the space agency will be advised to put its next pot of money into infrared astronomy and to neglect the Kepler mission, a scheme for sending an orbiting satellite to Mars (see Nature 24 February, p.647). Most probably, it will follow the advice proffered. There will be two consequences - European infrared astronomy (something of a corner in a large market) will prosper and the geophysicists of the Solar System (which is a contradiction in terms) will be even more offended.

The simple explanation of this state of affairs, where European planetary scientists are concerned, is too simple. There are too few launches of European satellites and other rocket-borne devices in prospect to satisfy legitimate claimants. As things are, the European Space Agency is able to plan for one exploit of a scientific character every eighteen months or so. Chauvinistically but also to save costs, it is biased towards the use of the Ariane rocket as a launching vehicle, but can from time to time be bullied into paying for an American Thor-Delta instead, as now arranged for this summer's launch of the European X-ray satellite called Exosat (see Nature 3 March, p.4). Planetologists complain that they are short-changed by the committees, but even solar physicists and astrophysicists argue that they could be more productive if there were more opportunities for extraterrestrial observations.

The more complicated answer is almost impossibly so. The most tangible part of it is the cost of planetary missions. The standard cost of a typical instrumental expedition such as Kepler is $\$ 500$ million or thereabouts, comparable with the cost of many sizeable particle accelerators or the annual operating budgets of even quite large universities. Astrophysically-directed Earth satellites, on the other hand, may often be an order of magnitude cheaper; much depends on whether the launcher and some of the instrumentation can be bought off the shelf. Although the harvest of understanding won by the latest Voyager spacecraft to Jupiter, Saturn and more distant points is still being brought in (Nature, passim) even the fondest Congress will not send them up as if they were fireworks on 4 July. President Reagan's budget for the coming financial year includes $\$ 300$ million for an instrument to map the surface of Venus by means of radar, the only substantial investment in planetary science now made public. The explanation of these high costs is not far to seek: the greater the distance, the greater the need for both broadcasting power (and thus of launching weight) and for pre-tested reliability. Planetary scientists could do themselves a service by worrying about costs.

The less defensible part of the planetologists' case, but also the more interesting, is that implied by the question "What is it for?". There are three kinds of responses, of which the grandest is the simple statement that planetary science is meant to explain how the Solar System came into being. Planetologists should therefore note what outsiders sense to be the case - that since measurements of planets beyond the Moon began to accumulate more quickly than their data could be assimilated, more than a decade ago, theorizing about the origin of the Solar System has tailed off. The people concerned are either too busy telling what the data are in all those reels of tape, or are in awe of them. Planetology is also defensible on the grounds that phenomena elsewhere may illuminate some occurring closer at hand, as an understanding of the Red Spot of Jupiter may yet help to explain the "blocking" of anticyclones in temperate terrestrial latitudes, and because there are probably many undiscovered phenomena yet to surprise us.

How, in these circumstances, should planetary scientists conduct themselves? Complaining at the committee procedures of the European Space Agency is the most obvious but the most negative course to follow. So long as the cost of planetary scientists' ambitions when added up outstrip the present cost of supporting the remainder of academic science, there is very little chance that they will be satisfied. A better tack would be to demonstrate to the rest of the scientific community (but also to legal entities such as the US Con- gress and the European Space Agency) that the data gathered in previous planetary missions are being used to the fullest. In the United States, unfortunately, this goal is compromised by the circumstance that the cost of launching something, almost anything, is more visible than the cost of analysing whatever data may be gathered. The American Astronomical Society has complained of next year's US budget, the Venus Radar Mapper notwithstanding, that an extra \$11 million is needed for the expeditious analysis of data already piled up by earlier projects. In Europe the same complaint is nevertheless valid.

So why should not the United States and Europe pool their resources on the analysis of past data about the Solar System, and on the planning of future projects? There is nothing but ephemeral chauvinism to deny that question. What planetary science most urgently needs is an international institute of planetary science, a free-living centre of research with access to data from everywhere. The National Aeronautics and Space Administration in the United States is in a mood for a deal along these lines, but would probably take offence if the centre were not alongside the Jet Propulsion Laboratory in California. The European Space Agency is in the same case but would prefer a site in the Low Countries. Planetary scientists, who are temporarily a thorn in the flesh of such agencies, should work out among themselves how the enterprise should be organized.

Planetary scientists must also work out among themselves some means of regulating their internal business in a seemly way. As things are, people complain that they are shy of putting forward imaginative proposals to the advisory committees for fear that their ideas will be stolen, if not by a fellow-national then by somebody else. The consequence of such theft is not merely injured pride but a potential loss of business for a home laboratory. This, too, is a problem that could be made to go away if there were a sufficiently independent international centre for planetary science, one sufficiently well-endowed with people to draw up a systematic and persuasive programme for the exploration of the Solar System by means of spacecraft carrying instruments. As things are, both in Europe and the United States, the prizes (if any) go to the clever instruments. Understanding where the Solar System came from is a secondary consideration. 